
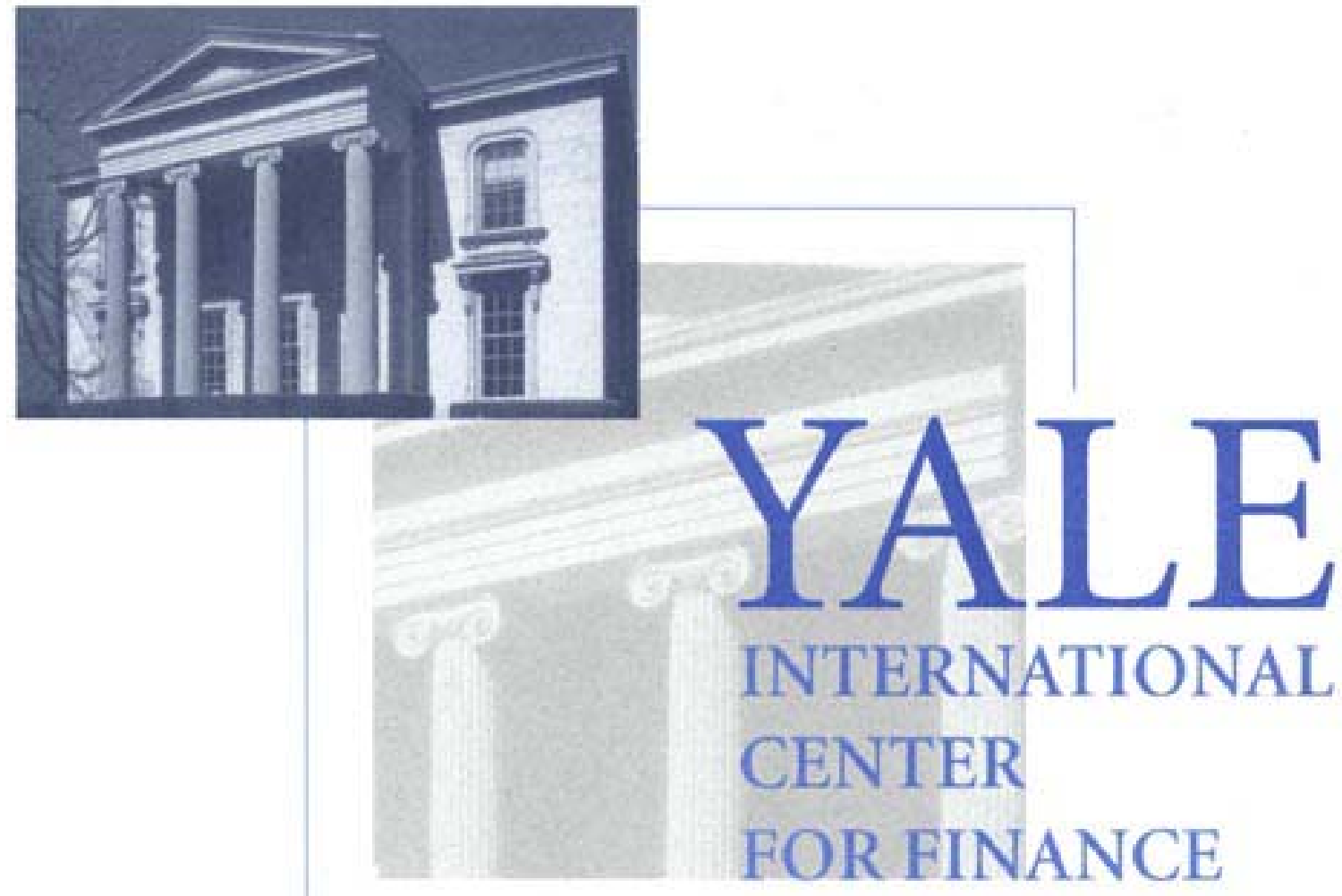

Yale ICF Working Paper No. 02-22

March 2002

\title{
WHAT MAKES AUTONOMOUS MANAGEMENT DO WELL?: CORPORATE GOVERNANCE WITHOUT EXTERNAL CONTROLS
}

\author{
Shinichi Hirota \\ Yale School of Management \\ Kohei Kawamura \\ University of Oxford
}

This paper can be downloaded without charge from the Social Science Research Network Electronic Paper Collection:

http://ssrn.com/abstract_id=302383 


\title{
What Makes Autonomous Management Do Well? Corporate Governance without External Controls"
}

\author{
Shin'ichi Hirota \\ School of Commerce, Waseda University \\ Yale School of Management \\ and \\ Kohei Kawamura \\ Nuffield College, University of Oxford
}

March 2002

\footnotetext{
${ }^{*}$ We appreciate the helpful comments and suggestions from Masahiko Aoki, Tomio Arai, Yasuhiro Arikawa, Hideshi, Itoh, Shyam Sunder, Misa Tanaka, Yasuhiko Tanigawa, Noriyuki Yanagawa, and seminar participants at Hitotsubashi, Waseda, Finance Research Workshop, JUTC (Rengo) Research Institute, Ministry of Economy, Trade and Industry, and Ministry of Finance.
} 


\title{
What Makes Autonomous Management Do Well? Corporate Governance without External Controls
}

\begin{abstract}
We propose a model of the widely held firm where management may behave on behalf of shareholders even without external controls. The model shows that there exists a corporate governance mechanism inside the firm where workers are employed on a long-term basis. When effort of young workers depends on managerial decision-making, they give implicit pressure on the managers, which may substitute control by shareholders. If this mechanism works fairly well, it is optimal for shareholders to leave the firm autonomous. We also discuss how the firm's internal factors (such as retention rate and business information sharing) and external environments (such as product market competition and labor market rigidity) affect the efficacy of this internal governance mechanism.
\end{abstract}

JEL classification: G34; J41 


\section{Introduction}

Is it possible that self-interested management do well without external controls? Much of the literature on corporate governance has focused on how the outsiders of the firm, such as shareholders or financial institutions, can discipline the managers in face of the agency problem. ${ }^{1}$ However, even in the U.S. or U.K. where corporate governance is widely regarded 'shareholder-oriented' and hostile takeovers are relatively frequent, hostile tender offers were not widely used until 1960s: they are a relatively recent innovation (Hansmann, 1996). ${ }^{2}$ In other economies such as Germany, France, or Japan, where takeovers have been very rare or almost non-existent, monitoring by financial institutions is supposed to be a major source of external pressure in these countries. However, usually they do not play an active role unless the firm is in serious financial distress. Debt itself may serve as a disciplinary mechanism (Jensen, 1986; Hart and Moore, 1995). However, as Mayer (1988) pointed out, large corporations in these countries typically obtain funds internally from retained earnings. ${ }^{3}$

Therefore, it should be natural to think that external controls such as takeovers or monitoring by financial institutions may not be necessary conditions for motivating corporate executives, although they should effectively mitigate the agency problem in certain circumstances. When can shareholders dispense with these measures, and when are they necessary? ${ }^{4}$

In this paper we examine internal governance mechanism to discipline management, using a simple framework that includes internal factors such as long-term employment or business information sharing as well as external factors such as labor market rigidity or product market

\footnotetext{
1 See, for example, Shleifer and Vishny (1997).

${ }^{2}$ However, as Allen and Gale (2000) summarize, the empirical evidence on the effectiveness of hostile takeovers is mixed.

${ }^{3}$ See also Dore, Lazonick and O'Sullivan (1999).

4 Allen and Gale (2000) develop some models to answer these questions. They stress that long term employment in the firm has the internal governance mechanism to managers. In this sense, our view shown later is similar to theirs. In addition, Burkart, Gromb and Panunzi (1997) consider the situation where too much control may inhibit managerial incentives.
} 
competition. Given that exercising external controls is costly, ${ }^{5}$ shareholders may choose to leave the firm autonomous. In the model workers who are employed on a long-term basis may give implicit pressure on management on behalf of shareholders. Unlike ordinary models of worker influence on management, however, workers in our model do not have any explicit participation or bargaining measures. Interestingly, it is the existence of the agency problem between management and workers mitigates the agency problem between shareholders and management.

We assume that managers have to monitor the workers in order to induce them to expend effort. When old workers in the firm obtain rents, a young worker provides effort even under less intensive monitoring if the manager does not engage in inefficient activities since it makes the survival of the firm more likely. The manager, who wants to avoid monitoring effort, may choose to good projects (pursue shareholders' interests) even if bad projects may give him substantial private benefit. It may be better for the manager to give up the private benefit, because it reduces monitoring effort necessary to induce young workers to work. There are four preconditions for this internal governance mechanism to work. First, there must be long-term employment. Otherwise management cannot reduce monitoring to young workers by choosing the good project. Second, employees must be able to observe (and understand) the manager's behavior. Third, the firm has to face competitive product market so that managerial misbehavior leads to risking the survival of the firm. ${ }^{6}$ Finally the labor market must be rigid at least to some extent.

We then examine some implications of this internal governance mechanism for shareholders' intervention policy. Shareholders can conduct monitoring and interfere, but only at substantial costs. To the extent that the internal governance mechanism assures that the manager is more than likely to pursue the shareholders' interests, they refrain from actively monitoring the firm. Only when the shareholders' value with intervention is larger than that with autonomous management, intervention should be conducted. Otherwise, it is optimal for shareholders not to intervene the management expecting that the manager to make a decision autonomously on behalf

\footnotetext{
5 We discuss these issues below.

6 The disciplinary role of product market competition is discussed recently by Schmidt (1997). Nickell (1997) finds robust evidence of positive effect of competition on corporate performance.
} 
of the shareholders.

This paper proceeds as follows. In Section II we set out a model of corporate governance without external controls or managerial incentive pay. In Section III, we analyze the worker incentives and manager's project choice and explore the possibility that the internal governance mechanism works well. In Section IV, we compare the shareholders' value under this internal governance to the value with shareholders intervention and examine the optimal intervention policy for shareholders. Section V concludes.

\section{The Model}

We assume that each identical firm in the economy consists of a manager, young worker, old worker, and shareholders. A risk-neutral manager works only for 1 period and is replaced by another in the next period. A risk neutral worker's career lasts for 2 periods. In each period he is either be employed or unemployed. His utility when unemployed is normalized to 0 . The workers employed by a firm are represented by the OLG (overlapping generations) structure. A young worker serves for the same firm for two periods unless he leaves at the end of the first period. Shareholders consist of many investors and have infinite time horizons.

The manager in charge can choose between two types of the project. Both types earn revenue $a$ in the current period if when both young and old workers provide effort and 0 if any of them shirks. We assume that $a$ is large enough so that the manager will induce the workers to exert effort. With one of the projects, called G-project, the firm continues to operate in the next period although the manager does not get a private benefit. When the manager chooses the other project, called B-project, the firm is liquidated after the end of the period with probability $p(0 \leq p \leq 1)$, but the manager himself enjoys private benefit B (See Table 1 ). ${ }^{7}$ In this setting it is implied that the manager's decision (project choice) affects the future of the firm, while the workers' action (effort)

\footnotetext{
${ }^{7}$ None of the qualitative results are affected when a firm with G-project is liquidated if the probability of liquidation is smaller than a firm with B-project.
} 
determines only its current performance (revenue) ${ }^{8}$ If G-project is implemented in every period, the firm will be in operation forever. We can interpret $p$ as the degree of product market competition the firm is facing. When the product market is more competitive, a firm that implements a 'bad' project is more likely to be liquidated.

The manager at $t$ has utility function:

$$
M=b+\gamma \pi-\Omega\left(m_{y}+m_{o}\right),
$$

where $b=B(b=0)$ if the manager chooses B-project (G-project). The manager receives a fraction $\gamma$ of the firm's gross profit $\pi=a-w_{y}-w_{o}$, where $w_{y}, w_{o}$ are wages for young and old workers, respectively. We assume that it is impossible to give monetary incentives with respect to the project choice, because of the asymmetric information between the manager and shareholders. That is, $\gamma$ is set only to give incentives to earn positive profit in the current period. ${ }^{9}$ To simplify the analysis we assume that the manager obtains rents in the sense that his participation constraint is not binding. This eliminates the effects of marginal changes of other parameters on $\gamma$.

Besides the project choice, the manager monitors the workers in order to induce them to exert effort. The monitoring intensity for young and old workers is represented by $m_{y}$ and $m_{o}$, respectively. $\Omega\left(m_{y}+m_{o}\right)$ is the monitoring costs incurred by the manager. We interpret $\Omega$ as a parameter representing difficulty of monitoring workers

The workers in each period decide whether to provide two levels of effort 0 or $e>0$. The utility of the old worker in period $t$ is

$$
U_{o}=w_{o}-e_{o},
$$

where $w_{o}$ is his wage and $e_{o}$ is the effort level which is 0 or $e$. If the old worker shirks $\left(e_{o}=0\right)$, there is probability $m_{o}$ that he will be caught. If caught shirking, he is dismissed immediately and becomes unemployed without being paid $\left(w_{o}=0\right)$.

The utility of the young worker in period $t$ is

\footnotetext{
${ }^{8}$ This assumption is not essential. If each party's action affects both the future and the current performance of the firm, it would strengthen (not weaken) the governance mechanism we consider.

${ }^{9}$ We treat $\gamma$ as a constant. When a large shareholder is absent, it would be difficult to set a managerial incentive scheme that maximises the shareholders' value, because the manger may effectively determine his pay on his own. See Bertrand and Mullainathan (2000).
} 


$$
U_{y}=w_{y}-e_{y}+\beta\left(w_{o}-e_{o}-s_{o}\right),
$$

where $w_{y}, e_{y}$ is his wage and effort level $(0$ or $e)$ in the current period, respectively. $\beta$ is the discount factor and $s_{o}$ is a turnover cost. $s_{o}$ equals to $s(>0)$ when he works in the different firm in the next period. We can interpret $s$ as search costs to find a new job or could reflect the loss of the worker's firm-specific human capital. On the other hand, $s_{o}$ equals to 0 when the young worker continues to work as an old worker in the same firm in the next period.

As in the case of the old worker, if the young worker shirks $\left(e_{y}=0\right)$, he will be caught with the probability of $m_{y}$. If caught, he is dismissed immediately without being paid $\left(w_{y}=0\right)$ and he is not hired by the same firm in the next period. Also, we introduce an exogenous retention rate $\lambda$, with which the young worker remains in the firm if he is not dismissed for shirking. $\lambda$ can be considered as the degree of long-term employment of the firm. We assume that if the young worker leaves, the firm replaces him with another old worker in the next period.

The shareholders receive dividend $(1-\gamma) \pi$ while the firm survives. They may actively intervene in the management and make the manager implement G-project but only at the expense of an ex ante cost $C$. It includes costs for information acquisition, administration, and so on. $C$ may be affected by country-specific institutional factors (e.g. legal rights for shareholders) as well as industry or firm specific variables. Firms in a country with better shareholder protection would generally have lower $C$. In contrast, a firm where the manager has more informational advantage may have larger $C$ even if it is located in a country guaranteeing wider shareholder rights.

At the beginning of each period, the manager observes private benefit $B$. He then decides whether to choose G-project or B-project. The workers cannot see the value of $B$, but they correctly observe the manager's project choice ( $\mathrm{G}$ or $\mathrm{B}$ ) with probability $\theta$. The value of $\theta$ has some possible interpretations. It can be thought of as the degree of business information sharing between management and workers ${ }^{10}$, or the workers' ability to understand how the firm is managed. In this paper we simply treat it as an exogenous variable. After choosing the project, the manager determines the intensity of monitoring workers, and the workers decide on their effort choice. At

\footnotetext{
${ }^{10}$ Kleiner and Bouillon (1988), Morishima (1991a) (1991b).
} 
the end of the period, the revenue is realized and the wage is paid. The shareholders may monitor the manager and make him implement G-project by incurring the cost $C$ at the beginning of each period. The timing is summarized in Figure 1.

\section{Corporate Governance without External Controls}

\section{A. Worker Incentives}

Since both young and old workers must exert effort to raise positive revenue, we first consider the old worker's incentive to do so. The incentive compatibility (IC) constraint of the old worker can be written as

$$
w-e \geq 0 \cdot m_{o}+w\left(1-m_{o}\right) .
$$

We assume that it is too costly to fully induce the workers' effort by means of "efficiency wage". Therefore, the manager has to elicit the workers' effort by monitoring them. The wage is determined in the labor market or collective bargaining, and the manager takes it as given. ${ }^{11}$ For notational simplicity we assume that the young and old worker receive the same wage $w$ and that $w-e-s \geq 0 .{ }^{12}$ The monitoring intensity ensuring the old worker's effort is given by

$$
m_{o} \geq \frac{e}{w} .
$$

Utility maximization (effort minimization) of the manager implies that (1) holds with equality, that is, $m_{o}=e / w$. Note that the manager's project choice $(\mathrm{G}$ or $\mathrm{B})$ is irrelevant to the old worker's IC, since he retires at the end of the period.

The incentive compatibility of the young worker is not as simple as that of the old worker. The reason is that the young worker's expected utility depends on whether the firm continues to operate in the next period, which is affected by the manager's project choice. We have three

\footnotetext{
${ }^{11}$ We may consider other wage determination mechanisms. What is necessary to our results is that a young worker who leaves the firm incurs some utility loss (as in $s$ ) compared with those who do not.

12 This assumption is not essential. Any results of this paper hold as long as $w_{y}>s$, which we believe is plausible.
} 
possible cases: the young worker observes G-project, B-project, or does not observe the manager's project choice. First let us consider the case where he observes G-project being implemented. The incentive compatibility constraint in this case is

$$
\begin{aligned}
& w-e+\beta[\lambda(w-e)+(1-\lambda)(w-e-s)] \geq \\
& \left(1-m_{y}\right)[w+\beta[\lambda(w-e)+(1-\lambda)(w-e-s)]]+m_{y}[0+\beta(w-e-s)] .
\end{aligned}
$$

As described earlier, if the young worker is caught shirking or leaves the firm he incurs search cost $s$. Rearranging the IC constraint we have the non-shirking monitoring intensity

$$
\underline{m}_{y}=\frac{e}{w+\beta \lambda s} .
$$

It is easy to see that the manager's monitoring intensity for inducing the young worker's effort is lower than that of the old worker. The reason is as follows. Having observed G-project, the young worker is certain that the firm will still continue to operate in the next period. Then he has more incentive to provide effort, expecting that he will be employed by the same firm in the next period as well (, which means he does not have to incur turnover cost $s$ ). Therefore, the manager does not have to monitor the young worker intensively and this reduces his monitoring cost. This is the manager's monitoring-cost-saving effect of choosing G-project.

Next is the case in which the young worker sees the manager choosing B-project. Having observed B-project, the young worker realizes that the firm will not exist in the next period with the probability of $p$. Then, he predicts that the probability of continuing to work in the same firm in the next period is $\lambda(1-p)$. In this case, the IC constraint of the young worker is given by

$$
\begin{aligned}
& w-e+\beta[\lambda(1-p)(w-e)+(1-\lambda(1-p))(w-e-s)] \geq \\
& \left(1-m_{y}\right)[w+\beta[\lambda(1-p)(w-e)+(1-\lambda(1-p))(w-e-s)]]+m_{y}[0+\beta(w-e-s)] .
\end{aligned}
$$

Hence we have the monitoring intensity

$$
\bar{m}_{y}=\frac{e}{w+\beta(1-p) \lambda s} .
$$

We should notice $\bar{m}_{y} \geq \underline{m}_{y}$. That is, with his choice of B-project being observed, the manager has to monitor the young worker more intensively (incurs more monitoring cost) than he does with 
G-project. The reason for this is following. With B-project, the young worker considers that the firm may not exist in the next period, and making effort in the current firm does not guarantee to be employed in the next period. Hence the young worker has less incentive to work.

Finally let us see the case in which the young worker does not observes the manager's project choice. We assume that even when he does not know whether the manager has chosen G-project or B-project, he has rational expectation about the probability that the manager implements G-project (or B-project). Suppose the young worker's subjective probability of G-project (B-project) being implemented is $\delta$ (or $1-\delta$ ). We will see later how $\delta$ is determined. Taking $\delta$ as given, we have the IC of the young worker:

$$
\begin{aligned}
& w-e+\beta[(\delta+(1-\delta)(1-p)) \lambda(w-e)+(1-(\delta+(1-\delta)(1-p)) \lambda)(w-e-s)] \geq \\
& \left.\left(1-m_{y}\right)[w+\beta[(\delta+(1-\delta)(1-p)) \lambda(w-e)+(1-(\delta+(1-\delta)(1-p)) \lambda)(w-e-s))]\right]+m_{y}[0+\beta(w-e-s)] .
\end{aligned}
$$

As in the previous cases utility maximization of the manager implies

$$
m_{y}^{*}=\frac{e}{w+\beta(\delta+(1-\delta)(1-p)) \lambda s} .
$$

Naturally, we find that $\bar{m}_{y t} \geq m_{y}^{*} \geq \underline{m}_{y}$.

All these things make it clear that G-project gives the young worker more incentive to provide effort and therefore the manager's monitoring cost is smaller with G-project than B-project. As a result, it may be of the manager's interest to choose G-project, although he can enjoy private benefit $B$ with B-project. This is what we call 'internal governance mechanism' in this paper. We will see the details of this mechanism by examining manager's project choice in the following subsection.

\section{B. Manager's Project Choice}

Let us consider a manager's project choice. We begin with the comparison of the two projects in terms of the manager's expected utility. His expected utility when he implements G-project is

$$
M_{g}=\gamma \pi-\left[\theta \Omega\left(\underline{m}_{y}+m_{o}\right)+(1-\theta) \Omega\left(m_{y}^{*}+m_{o}\right)\right] .
$$

The first term $(\gamma \pi)$ represents managerial compensation, and the second term is the manager's 
expected cost of monitoring workers. Similarly, when he implements B-project, his expected utility is

$$
M_{b}=B+\gamma \pi-\left[\theta \Omega\left(\bar{m}_{y}+m_{o}\right)+(1-\theta) \Omega\left(m_{y}^{*}+m_{o}\right)\right] .
$$

Hence, the manager will opts for G-project if $M_{g} \geq M_{b}$. We can rewrite this condition as

$$
\theta \Omega\left(\bar{m}_{y}-\underline{m}_{y}\right) \geq B .
$$

The left hand side is the monitoring-cost-saving effect of G-project (compared with B-project), and the right hand side is the private benefit with B-project. The manager chooses G-project (B-project) if the former is larger (smaller) than the latter.

As it seems natural to suppose that the manager's private benefits with projects are unobservable to others and different among different managers, let us assume that $B$ is a random variable and have probability distribution $F(B)$ with support $[0, \infty)$. Thus the probability that the manager chooses G-project, $\delta$, is $F\left(\theta \Omega\left(\bar{m}_{y}-\underline{m}_{y}\right)\right)$. We have assumed that the young worker (as well as shareholders) correctly reckons this probability. This implies that,

$$
\delta=F\left(\theta \Omega\left(\frac{e}{w+\beta(1-p) \lambda s}-\frac{e}{w+\beta \lambda s}\right)\right)
$$

$\delta$ is a variable that plays a central role in our model. It is the degree to which the manager autonomously chooses the good project for the company's future even if the project does not give him private benefit.

Now we can see how internal and external variables of the firm affect the probability that the manager implements G-project $(\delta)$. See Table 2. First, a rise in the worker's retention rate $\lambda$ increases $\delta$. This suggests that the higher degree of the long-term employment is observed, the more the manager is likely to choose the good project. Second, $\delta$ is increasing in $\theta$. The high probability that the worker observes the manager's project choice (in other words, high business information sharing between the management and workers) disciplines the manager. Third, $\delta$ is also increasing in $\Omega$. As it becomes difficult to monitor the workers' effort ( $\Omega$ becomes greater), the monitoring-cost-saving effect of G-project increases and it makes G-project more attractive. Fourth, interestingly, a labor market variable also affects $\delta$; there exists a positive relation between s and $\delta$. 
The more it becomes difficult to find a job (higher $s$ ), the more likely the manager is to implement G-project. Finally, we can point out that $\delta$ is increasing in $p$, the probability that the firm goes bankrupt when the manager chooses B-project. This suggests that the manager is more likely to choose G-project when the firm is involved in more competitive product market. ${ }^{13}$

\section{Shareholders' Value}

We define shareholders' value of the firm as the net present value of the dividend stream. We assume that no retained earnings are left in the firm. Hence, each period shareholders receive the firm's profits net of managerial compensation, $(1-\gamma) \pi$, as long as the firm survives. If the manager implements B-project the firm is dissolved with probability $p$ so that the dividend from the next period onward may be 0 . Therefore the shareholders always prefer G-project to B-project in our model. In this setting, we discuss shareholders' value (i) when the manager has autonomy and (ii) when the shareholders intervene in the management.

\section{Shareholder's Value under Autonomy}

First we consider the situation where the shareholders do not engage in controlling the firm. The shareholders merely own it and receive the dividend as long as it survives. In this case, as shown in the last section, the manager implements G-project with probability $\delta$, and hence the probability of survival of the firm is $\delta+(1-\delta)(1-p)$. The shareholders' value is thus

$$
V_{N}=\frac{(1-\gamma) \pi}{1-(\delta+(1-\delta)(1-p)) \beta} .
$$

It is easy to see that $\partial V_{N} / \partial \delta \geq 0$. Together with Table 2 it implies that rises in $\lambda, \theta, \Omega$, and $s$ increases $V_{N}$. This suggests that long-term employment, worker ability to observe managerial behavior (business information sharing), difficulty of monitoring workers and labor market rigidity increases the shareholders' value of the firm under autonomy. This is because they enhance the

\footnotetext{
${ }^{13}$ This effect is similar to what Schmidt (1997) calls "threat-of-liquidation effect".
} 
internal mechanism that forces the manager to choose G-project de facto on behalf of the shareholders. ${ }^{14}$ The effect of product market competition $p$ on the shareholders' value is ambiguous, however. While increasing competition makes the manager more likely to opt for G-project, it reduces the probability of survival in case he chooses B-project.

\section{Shareholder Intervention}

Next, let us consider the case where shareholders can intervene into the managerial decision-making ex ante at some cost $C$. Since they prefer G-project, they will always make the manager implement G-project if they intervene. This means that with the shareholders' intervention the firm certainly survives in each period and continues to operate infinitely. Therefore, in this case, the shareholders' value net of intervention costs is

$$
V_{I}=\frac{(1-\gamma) \pi-C}{1-\beta} .
$$

\section{Optimal Intervention Policy}

Now we are in a position where we discuss the optimal intervention policy for the shareholders. The shareholders intervene the management when the value with intervention is larger than that under autonomy, that is, $V_{I} \geq V_{N}$. This is represented in Figure 2, which shows the relations between the shareholders' values $\left(V_{I}\right.$ and $\left.V_{N}\right)$ and $\delta$. Let $\delta^{*}$ be the point at which the shareholders are indifferent between intervention and no intervention $\left(V_{I}=V_{N}\right)$.

If $\delta<\delta^{*}, V_{I}$ is larger than $V_{N}$. Therefore, it is optimal for the shareholders to intervene the management at the expense of $C$. This is because when the probability that the autonomous manager implements G-project $(\delta)$ is relatively small, the shareholder intervention that forces the manager to implement G-project has a large effect on the value. In this case, shareholder activism

\footnotetext{
${ }^{14}$ We should note that these results are subject to simplifying assumptions in our model. If we assume that the labor market rigidity makes the firm incur larger hiring costs, which we do not take account of, the effect of labor market rigidity $s$ on the value of the firm is ambiguous. In addition, if the manager's participation constraint is binding a marginal change in $\Omega$ may increase $\gamma$, which makes also the effect of $\Omega$ ambiguous.
} 
should be observed.

If $\delta>\delta^{*}$, on the other hand, $V_{N}$ is larger than $V_{I}$. This indicates that it is beneficial for shareholders not to intervene in the management, because they expect that the manager is likely to implement G-project voluntarily. Therefore, in this case, the intervention will not occur. This result implies that high $\delta$ firms, which has internal characteristics such as long-term employment, business information sharing and the difficulty in monitoring workers, and an external factor such as rigid labor markets, tend to be autonomously managed. In other words, the manager is not subject to external (i.e., shareholders') controls in these firms. ${ }^{15}$

\section{Conclusion}

In this paper we have proposed a corporate governance mechanism in which the manager may behave on behalf of shareholders even without external control or explicit managerial incentive schemes. We find that both internal and external variables affect the efficacy of this internal governance mechanism. The internal variables include the degree of long-term employment, business information sharing between management and workers, and difficulty of monitoring workers. The external variables relevant to internal governance are labor market rigidity and product market competition. They may have positive effect on the value of the firm when it is managed autonomously, since they enhance the internal governance mechanism.

We then have examined some implications of the model for shareholder intervention. When the internal governance mechanism works fairly well, the shareholders may not have incentive to monitor and control the management directly, because the benefit of doing so may be too small. If it is the case, managerial autonomy is observed as a consequence of shareholders'

\footnotetext{
15 We should note that $V_{I}$ is the shareholders' value in the case where the shareholders intervene in management every period. It is possible to consider partial intervention strategies that the shareholders intervene in some periods and do not intervene in the other periods. We can prove that the shareholder values under these partial intervention strategies are smaller than $V_{I}\left(V_{N}\right)$ when $\delta<\delta^{*}$ (when $\delta>\delta^{*}$ ). Therefore, considering partial intervention strategies does not change our results on the shareholders optimal intervention policy.
} 
optimal decision. This result explains the fact that shareholders are, in general, passive to management decisions.

Our model may provide some important insights into the cross-country and cross-industry difference and historical change in the form of corporate governance. In an economy or industry where product markets are competitive and yet the labor market is rigid, it is likely that internal governance has comparative advantages over external controls. Also, at the firm level, the firm with long-term employment, complex organizational structure, or high information sharing may be managed autonomously. Autonomous managers may work for the sake of the value of the firm. 


\section{References}

Allen, Franklin and Douglas Gale (2000) Comparing Financial Systems. Cambridge, MA: MIT Press.

Bertrand, Marianne and Sendhil Mullainathan (2000) "Agents without Principals," American Economic Review Papers and Proceedings, 90: 203-208.

Burkart, Mike, Denis Gromb and Fausto Panunzi (1997) "Large Shareholders, Monitoring, and the Value of the Firm," Quarterly Journal of Economics, 112, 693-728.

Dore, Ronald, William Lazonick, and Mary O'Sullivan (1999) "Varieties of Capitalism in the Twentieth Century," Oxford Review of Economic Policy, 15, 202-220.

Hansmann, Henry (1996) The Ownership of Enterprise. Cambridge, MA: Belknap Press.

Hart, Oliver and John Moore "Debt and Seniority: An Analysis of the Role of Hard Claims in Constraining Management," American Economic Review, 85, 567-585.

Kleiner, Morris M. and Marvin L. Bouillon (1988) "Providing Business Information to Production Workers: Correlates of Compensation and Profitability," Industrial and Labor Relations Review, 41, 605-17.

Mayer, Colin (1988) "New Issues in Corporate Finance," European Economic Review, 32, 1167-1188.

Morishima, Motohiro (1991a) "Information Sharing and Collective Bargaining in Japan: Effects on Wage Negotiation," Industrial and Labor Relations Review 44, 469-487.

Morishima, Motohiro (1991b) “Information Sharing and Firm Performance in Japan," Industrial Relations 30, 37-61.

Nickell, Stephen (1996) "Competition and Corporate Performance," Journal of Political Economy 104, 724-746.

Rajan, Raghuram, and Luigi Zingales (2000) "The Governance of the New Enterprise" in Corporate Governance, X. Vives (ed.) Cambridge, UK: Cambridge University Press.

Schmidt, M. Klaus (1997) "Managerial Incentives and Product Market Competition", Review of 
Economic Studies 64: 191-213.

Shleifer, Andrei and Robert W. Vishny (1997) “A Survey of Corporate Governance,” Journal of Finance, 52 (2): 737-783.

Zingales, Luigi (2000) “In Search of New Foundations,” Journal of Finance, 55 (4): 1623-1653. 


\begin{tabular}{|c|c|c|}
\hline & G-project & B-project \\
\hline Revenue (with $e$ ) & $a$ & $a$ \\
\hline Private Benefit & 0 & $B$ \\
\hline Next Period & Operation & $\begin{array}{l}\text { Liquidation } \\
\text { with Prob } p\end{array}$ \\
\hline
\end{tabular}

Table 1

Comparative Statics on $\delta$

\begin{tabular}{|c|c|c|c|c|}
\hline$\lambda$ & $\theta$ & $\Omega$ & $s$ & $p$ \\
\hline+ & + & + & + & + \\
\hline
\end{tabular}

Table 2 


\section{Timing}

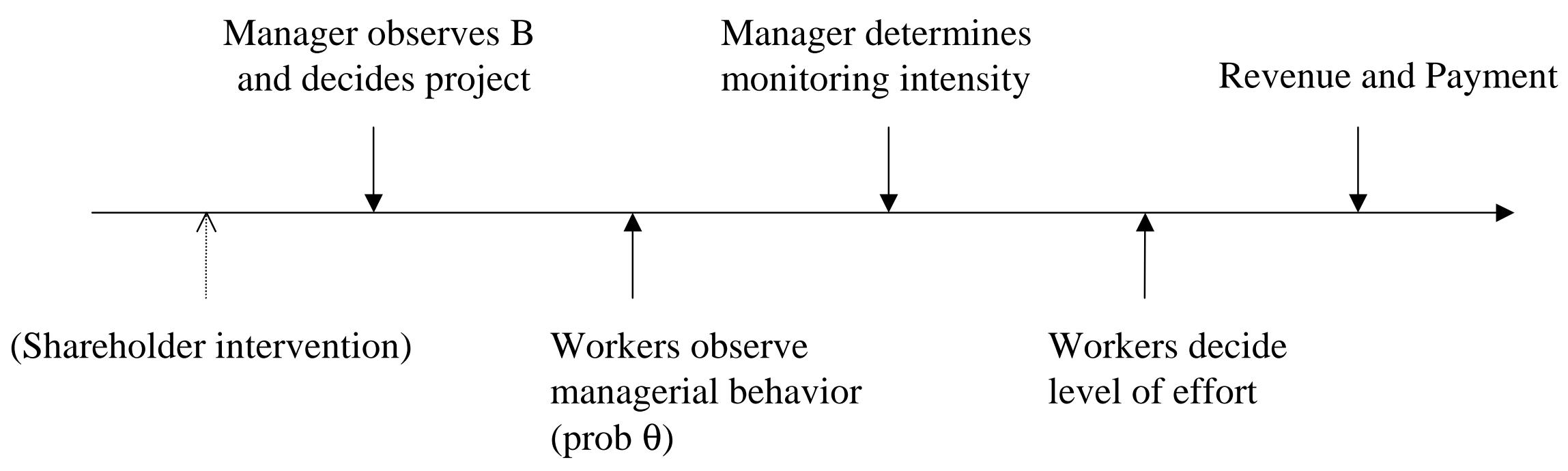

Figure 1 


\section{Monitoring by Shareholders}

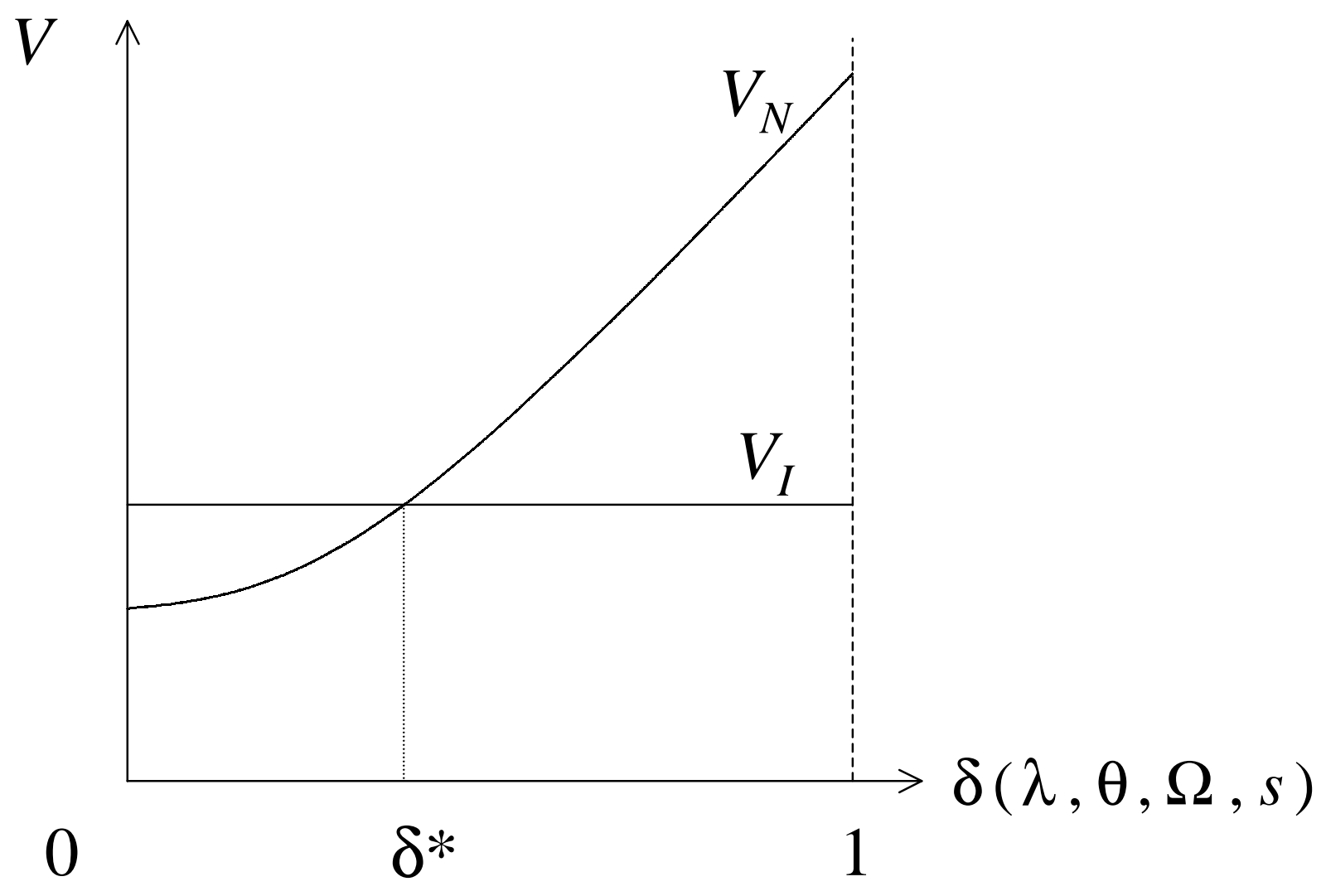

Figure 2 